\title{
Níveis de fósforo, cobre, cobalto e zinco em bubalinos (Bubalus bubalis) na llha de Marajó, Estado do Pará1
}

\author{
Cleyton P. Pinheiro ${ }^{*}$, Henrique A. Bomjardim², Stefano J.T. Andrade 2 , Kelson \\ C.F. Faial ${ }^{3}$, Carlos M.C. Oliveira ${ }^{2}$ e José Diomedes Barbosa ${ }^{2}$
}

ABSTRACT.- Pinheiro C.P., Bomjardim H.A., Andrade S.J.T., Faial K.C.F., Oliveira C.M.C. \& Barbosa J.D. 2011. [Levels of phosphorus, copper, cobalt and zinc in water buffaloes (Bubalus bubalis) on Marajo Island, Pará.] Níveis de fósforo, cobre, cobalto e zinco em bubalinos (Bubalus bubalis) na Ilha de Marajó, Estado do Pará. Pesquisa Veterinária Brasileira 31(3):193-198. Central de Diagnóstico Veterinário, Universidade Federal do Pará, Campus Castanhal, Rua Maximino Porpino da Silva 1000, Pirapora, Castanhal, PA 68740080, Brazil. E-mail: cleytonpinheiro@ hotmail.com

The study comprised 104 adults buffaloes, without distinction of race and sex, reared extensively, without supplementation, in native pastures of low nutritional quality, in the municipalities of Breves, Cachoeira do Arari, Salvaterra and Soure, Marajo Island, Pará. Samples of liver, bone and blood were collected from 26 animals in the municipality of Salvaterra, from 38 animals in the municipality of Soure, from 20 animals in the municipality of Breves and from 20 animals in the municipality of Cachoeira do Arari. Determination of the levels of phosphorus in the blood serum and bone ash, and of the specific gravity of bone, and of cobalt, copper and zinc in liver tissue were performed. The average phosphorus concentrations in blood serum $(6.26 \mathrm{mg} / \mathrm{dl})$ and bone $(10.77 \%)$, the percentage of ash $(60.87 \%)$ and specific gravity $(1.59 \mathrm{~g} / \mathrm{ml})$ of bone were lower than the critical levels established for cattle, characterizing phosphorus deficiency. The average concentrations of copper (5.57ppm) and zinc (27.05ppm) was considered low when compared with reference values, characterizing deficiency for these elements. In the case of cobalt when considering the detectable and undetectable values by the methodology, it was observed that $51.92 \%$ of the animals had levels below the reference, indicating the occurrence of cobalt deficiency in these animals. It is emphasized that the deficiencies of copper and zinc were the most severe since all animals studied showed deficient levels of these elements.

INDEX TERMS: Phosphorus, copper, cobalt, zinc, buffaloes, Marajo Island.

RESUMO.- Foram estudados 104 bubalinos, adultos, sem distinção de raça e sexo, criados extensivamente, sem suplementação, em pastagens nativas de baixa qualidade nutricional, dos municípios de Breves, Cachoeira do Arari, Salvaterra e Soure, Ilha de Marajó, Pará. Realizou-se coleta de amostras de fígado, osso e sangue de 26 animais do município de Salvaterra, 38 animais do município de

\footnotetext{
${ }^{1}$ Recebido em 2 de agosto de 2010.

Aceito para publicação em 20 de setembro de 2010.

2 Central de Diagnóstico Veterinário (CEDIVET), Universidade Federal do Pará (UFPA), Campus Castanhal, Rua Maximino Porpino da Silva 1000, Castanhal, PA 68740-080, Brasil. *Autor para correspondência: cleytonpinheiro@ hotmail.com

${ }^{3}$ Laboratório de Toxicologia, Setor de Meio Ambiente, Instituto Evandro Chagas, Rodov. BR $316 \mathrm{Km} 7$ Levilândia, Ananindeua, PA 67000-000, Brasil.
}

Soure, 20 animais do município de Breves e 20 animais do município de Cachoeira do Arari. Foram realizadas determinações dos teores de fósforo, no soro sanguíneo e no osso, do percentual de cinzas e da densidade específica no tecido ósseo, e de cobalto, cobre e zinco no tecido hepático. Observou-se que a média das concentrações de fósforo no soro sanguíneo $(6,26 \mathrm{mg} / \mathrm{dl})$ e no osso $(10,77 \%)$, a percentagem de cinzas $(60,87 \%)$ e a densidade específica $(1,59 \mathrm{~g} / \mathrm{ml})$ do osso foram inferiores aos níveis críticos estabelecidos para bovinos, caracterizando deficiência de fósforo. As concentrações médias de cobre (5,57ppm), e zinco $(27,05 \mathrm{ppm})$ foram consideradas baixas quando comparadas com valores de referência, caracterizando deficiência para estes elementos. No caso do cobalto, quando se considerou os valores detectáveis e não detectáveis pela metodologia observou-se que $51,92 \%$ dos animais 
apresentaram níveis inferiores aos de referência, demonstrando a ocorrência da deficiência de cobalto nesses animais. Ressalta-se que as deficiências de cobre e zinco demonstraram uma maior gravidade já que todos os animais estudados apresentaram níveis deficientes nesses elementos.

TERMOS DE INDEXAÇÃO: Fósforo, cobre, cobalto, zinco, bubalinos, Ilha de Marajó.

\section{INTRODUÇÃO}

A Ilha de Marajó, um arquipélago localizado nas margens do rio Amazonas, possui o maior rebanho bubalino do país, criado, sobretudo, em regime extensivo, em solos distróficos, com pastagens de baixa qualidade nutricional e suplementação mineral bastante precária. Nesse sistema, os índices de produtividade dos bubalinos dessa llha ainda estão muito abaixo do seu verdadeiro potencial.

O búfalo se torna uma alternativa para a população da Ilha de Marajó, devido principalmente à sua adaptabilidade. Entretanto, o Marajó possui enormes fazendas, que na sua maioria não possui cercas, o que impossibilita o controle do rebanho e a utilização de técnicas produtivas, tornando os manejos sanitários e nutricional bastante precários, predispondo esses animais a diversas enfermidades, dentre elas as deficiências minerais.

Devido às próprias características da llha de Marajó, a alimentação através de pastagens de boa qualidade e da suplementação mineral no cocho, se torna bastante difícil. Dessa forma, verificou-se que em fazendas localizadas em diferentes municípios da llha de Marajó, os rebanhos bubalinos apresentavam sinais clínicos, muitas vezes severos, de deficiências minerais, principalmente de fósforo, cobre e cobalto. Observou-se também, que muito animais apresentavam deficiências leves ou moderadas, que causavam redução na produtividade desses animais, levando a prejuízos econômicos sérios que muitas vezes não são percebidos pelos proprietários.

No Estado do Pará, as deficiências de fósforo, cobre e cobalto em bovinos e bubalinos, são comuns e muitas vezes severas (Barbosa et al. 2005).

As deficiências de minerais são tradicionalmente estudadas a partir da análise do solo e das forragens, onde os animais estão localizados. Entretanto, devido às variações na disponibilidade, interferências dos diferentes minerais e habilidade animal em melhorar ou reduzir absorção, o diagnóstico das deficiências minerais no animal deve, preferencialmente, ser abordado por intermédio da monitoração dos níveis nos fluidos e tecidos corpóreos (Tokarnia et al. 1999). A análise de material proveniente dos animais permite verificar de forma mais direta, com maior rapidez e facilidade, as deficiências existentes, com menor risco de erros na interpretação dos resultados (Boyazoglu et al. 1972, Miller \& Stake 1974, Mendes 1977, Underwood 1981, Conrad 1984). Segundo Tokarnia et al. (2000), amostragens de fígado e osso permitem chegar a conclusões bastante seguras sobre a ocorrência de deficiências minerais em extensas regiões, com um número relativamente pequeno de amostras.

Este trabalho teve por objetivo determinar os níveis de fósforo, no soro sanguíneo e no osso, percentual de cinzas e densidade específica no osso, e de cobre, cobalto e zinco no fígado de bubalinos, oriundos dos municípios de Breves, Cachoeira do Arari, Salvaterra e Soure, Ilha de Marajó, Estado do Pará.

\section{MATERIAL E MÉTODOS}

Foram coletadas amostras de 104 animais da espécie bubalina, adultos, sem distinção de raça e sexo, criados extensivamente, em pastagem nativa, nos campos da llha de Marajó, Pará. A coleta foi realizada em dois matadouros no município de Breves, Ilha de Marajó, Pará, em um matadouro no município de Castanhal, Pará e em animais sacrificados, sendo que todos os animais eram oriundos dos municípios de Breves, Cachoeira do Arari, Salvaterra e Soure, Ilha de Marajó, Pará. Foram coletadas amostras de 96 animais em matadouros e de 8 animais sacrificados.

A quantidade de amostras coletadas por município e o mês de realização dessas coletas estão dispostos no Quadro 1.

É importante ressaltar que os animais eram transportados diretamente de seu município de origem para o matadouro, e eram abatidos para consumo. No caso dos animais necropsiados, todos foram sacrificados em seus municípios de origem.

\section{Colheita de sangue}

As 104 amostras de sangue foram coletadas através de venopunção da jugular em tubos estéreis a vácuo de $5 \mathrm{ml} ; 96$ foram coletados na linha de abate, logo após a insensibilização, e 8 foram coletados antes do sacrifício dos animais, para realização das necropsias. O sangue foi centrifugado (3.000 rpm por 5 minutos) e logo após, o soro foi armazenado em frascos de polietileno (ependorf) e congelado a $-20^{\circ} \mathrm{C}$ até a análise.

\section{Coleta de tecido ósseo e fígado}

Foram coletados 89 fragmentos de ossos, sendo que destes, 44 foram retirados do terço médio da $12^{\text {a }}$ costela e 45 do corpo da mandíbula. As informações sobre quantidade de amostra coletada por município e o mês em que foi realizada estão dispostas no Quadro 1.

A coleta era feita com a utilização de uma serra desinfetada para retirada do fragmento ósseo de aproximadamente $20 \mathrm{~g}$. Logo após a retirada o fragmento era armazenado em saco plástico, identificado e congelado a $-20^{\circ} \mathrm{C}$.

Quadro 1. Quantidade de amostras coletadas por município da Ilha de Marajó e o mês de realização dessas coletas

\begin{tabular}{|c|c|c|c|c|}
\hline Municípios & Sangue & Fígado & Osso & $\begin{array}{l}\text { Mês de } \\
\text { coleta }\end{array}$ \\
\hline Breves & 20 & 20 & 20 & Maio $^{a}$ \\
\hline Cachoeira do Arari & 20 & 20 & 20 & Maio \\
\hline Soure & 26 & 26 & 26 & Setembro ${ }^{b}$ \\
\hline Salvaterra & 38 & 38 & 23 & Setembro \\
\hline Total de amostras & 104 & 104 & 89 & \\
\hline
\end{tabular}

a Mês do ano que pertence ao período de máxima precipitação pluviométrica.

b Mês do ano que pertence ao período de mínima precipitação pluviométrica. 
As amostras de fígado foram coletadas nos matadouros, na linha de abate, e durante a realização das necropsias. Foram coletados 104 fragmentos, de aproximadamente $200 \mathrm{~g}$, do lobo caudal do fígado com uma faca de aço inoxidável. As amostras foram armazenadas em sacos plásticos, identificadas e congeladas a $-20^{\circ} \mathrm{C}$.

\section{Dosagem de fósforo no soro sanguíneo e no osso}

As análises dos teores de fósforo inorgânico no soro sanguíneo foram realizadas no Laboratório de Patologia Clínica da Central de Diagnóstico Veterinário (CEDIVET) da Universidade Federal do Pará através de teste colorimétrico utilizando Kits reagentes no aparelho semi-automático de bioquímica Bioplus 2000.

No osso foi removido todo o tecido mole e material medular, através de jatos de água deionizada; depois, as amostras foram pesadas ao ar e na água, para obtenção do peso fresco e do volume, e secadas em estufa a $105^{\circ} \mathrm{C}$ durante $12 \mathrm{~h}$. Após, foram desengorduradas com éter etílico no extrator soxlet durante 48 horas. Depois de desengorduradas, espalhou-se o osso para secar (aproximadamente 3 horas) até que o odor de éter não fosse mais detectado. As amostras em seguida foram colocadas novamente para secar por 12 horas a $105^{\circ} \mathrm{C}$ em estufa. Os ossos secos e livres de gordura foram pesados, para obtenção do peso seco desengordurado, e calcinados em mufla a $600^{\circ} \mathrm{C}$ durante 12 horas. Após, as amostras calcinadas foram trituradas em gral e pistilo para obtenção das cinzas, que foram pesadas, amostradas entre 0,5 e 0,6g e armazenadas em tubos de vidros estéreis (adaptado de Fick et al. 1980).

As cinzas foram solubilizadas pela digestão com $3 \mathrm{ml}$ de $\mathrm{HNO}_{3}$ supra-puro, a uma concentração de $65 \%$, $1 \mathrm{ml} \mathrm{de} \mathrm{H}_{2} \mathrm{O}_{2}$, a uma concentração de $30 \%$ e $1 \mathrm{~mL}$ de $\mathrm{HCL}$ supra-puro, a uma concentração de $37 \%$, e após foram diluídas com água deionizada, para formar soluções para análise de cálcio e fósforo (adaptado das técnicas de Nomura et al. 2005).

\section{Determinação da densidade específica e do percentual de cinzas no osso}

O percentual de cinzas ósseas foi determinado de acordo com as recomendações de Mendes (1977). Todos os resultados foram expressos em percentagem, tendo como base a matéria seca livre de gordura. O cálculo da densidade óssea (d) foi efetuado em osso fresco a partir da pesagem das amostras ao ar $(\mathrm{m})$ com posterior aferição do volume $(\mathrm{v})$, sendo considerado: $d=m / v$, expresso em $\mathrm{g} / \mathrm{cm}^{3}$, segundo descrição de Fick et al. (1980).

\section{Determinação de cobre, cobalto e zinco no fígado}

As amostras de fígado, depois de descongeladas, foram secas em estufa a $105^{\circ} \mathrm{C}$, pesadas em balança de precisão com peso que variava entre 0,5-0,6g e acondicionadas em tubos de vidros estéreis de $5 \mathrm{ml}$. Posteriormente, as amostras foram submetidas a processos de digestão ácida e pré-tratamento químico, sendo digeridas em um sistema fechado, adicionando $7 \mathrm{ml}$ de $\mathrm{HNO}_{3}$ supra-puro, a uma concentração de $65 \%$, e $0,5 \mathrm{ml}$ de $\mathrm{H}_{2} \mathrm{O}_{2}$ a uma concentração de $30 \%$ e deixadas a temperatura ambiente por 12 horas. Na seqüencia, o processo de digestão foi complementado por aquecimento através de um forno de microondas MarsXpress - CEM Tecnology Inside durante 50 minutos. Após, as amostras foram aferidas ao volume final de $20 \mathrm{ml}$. Os brancos analíticos foram prepara- dos pelo mesmo procedimento sem a adição da amostra (Adaptado das técnicas de Nomura et al. 2005).

\section{Análises espectrométricas}

As determinações de Cobalto, Cobre e Zinco foram realizadas através de Espectrometria de Emissão Ótica com Plasma Induzido (ICP OES), modelo Vista-MPX CCD simultâneo (Varian, Mulgrave, Austrália), configuração axial e equipado com um sistema de amostragem automático (SPS-5). O controle das condições operacionais do ICP OES foi realizada com o software ICPExpert Vista (Adaptado das técnicas de Nomura et al. 2005). Os limites de detecção desta metodologia foi de $0,003 p p m$ para cobalto, de 0,002ppm para cobre e de $0,002 \mathrm{ppm}$ para zinco. Todos os resultados foram expressos em ppm, baseados na matéria seca de fígado.

O método analítico empregado para a determinação de fósforo obedeceu ao procedimento e recomendações descritas no Procedures Manual HACH-Espectrophotometer e foram determinados por espectrofotometria no equipamento DR2800 da HACH® (Hach Company 2008). Todos os resultados foram expressos em porcentagem, baseados no osso seco livre de gordura.

\section{RESULTADOS E DISCUSSÃO}

Todas as concentrações obtidas neste estudo foram comparadas com os valores de referência para a espécie bovina, estipulados por Little (1972), Underwood (1977), McDowell et al. (1984), Valdes et al. (1988) e Riet-Correa \& Timm (2007) e estão descritas no Quadro 2.

Os valores médios de fósforo, no soro sanguíneo e no osso, da densidade óssea e do percentual de cinzas no tecido ósseo, e de cobre, cobalto e zinco no tecido hepático são apresentados no Quadro 2.

A quantidade e porcentagem dos animais deficientes, sub-deficientes e valores adequados de fósforo no soro sanguíneo e no osso, da densidade óssea e do percentual de cinzas no tecido ósseo, e de cobre, cobalto e zinco no tecido hepático estão dispostos no Quadro 3.

Na determinação do nível de fósforo inorgânico no soro sanguíneo observou-se média de $6,26 \mathrm{mg} / \mathrm{dl} \pm 1,81$, sendo que $42(40,38 \%)$ animais apresentaram valores normais,

\begin{tabular}{|c|c|c|c|}
\hline \multirow[t]{2}{*}{ Variáveis } & \multicolumn{2}{|c|}{ Valores de referência ${ }^{a}$} & \multirow{2}{*}{$\begin{array}{l}\text { Média } \\
\text { e DPb }\end{array}$} \\
\hline & $\begin{array}{l}\text { Deficiente } \\
\text { ou inferior }\end{array}$ & $\begin{array}{c}\text { Sub- } \\
\text { deficiente }\end{array}$ & \\
\hline Fósforo (Soro)(mg/dl) $)^{g}$ & $<4,00$ & $4,00-7,00$ & $6,26 \pm 1,81$ \\
\hline Fósforo (Osso)(\%) & $<11,50$ & - & $10,77 \pm 2,00$ \\
\hline Densidade óssea $(\mathrm{g} / \mathrm{ml})^{f}$ & $<1,69$ & - & $1,59 \pm 0,18$ \\
\hline$\%$ de $\operatorname{Cinzas}(\%)^{\mathrm{e}}$ & $<66,80$ & - & $60,87 \pm 2,17$ \\
\hline Cobre $(p p m)^{d}$ & $<100,00$ & $50-100$ & $5,57 \pm 7,60$ \\
\hline Cobalto $(p p m)^{d}$ & $<0,05$ & $0,05-0,12$ & $0,36 \pm 0,33$ \\
\hline Zinco $(p p m)^{d}$ & $<100,00$ & - & $27,05 \pm 13,12$ \\
\hline
\end{tabular}

a Valores de referência para a espécie bovina, ${ }^{b}$ Desvio padrão, ${ }^{c}$ McDowell et al. (1984), d Underwood (1977), ${ }^{\mathrm{e}}$ Little (1972), ${ }^{\dagger}$ Valdes et al. (1988), g Riet-Correa \& Timm (2007). 


\begin{tabular}{|c|c|c|c|c|c|c|}
\hline \multirow[t]{2}{*}{ Variáveis } & \multicolumn{2}{|c|}{ Deficiente ou inferior } & \multicolumn{2}{|c|}{ Sub-deficiente } & \multicolumn{2}{|c|}{ Adequado } \\
\hline & Quantidade & $\%$ & Quantidade & $\%$ & Quantidade & $\%$ \\
\hline Fósforo (Soro) (mg/dl) & 12 & 11,54 & 50 & 48,08 & 42 & 40,38 \\
\hline Fósforo (Osso) (\%) & 51 & 57,30 & - & - & 38 & 42,70 \\
\hline Densidade óssea $(\mathrm{g} / \mathrm{ml})$ & 63 & 70,79 & - & - & 26 & 29,21 \\
\hline Cinzas (\%) & 89 & 100 & - & - & - & - \\
\hline Cobre (ppm) & 104 & 100 & - & - & - & - \\
\hline Cobalto (ppm) & 25 & 24,04 & 29 & 27,88 & 50 & 48,08 \\
\hline Zinco (ppm) & 104 & 100 & - & - & - & - \\
\hline
\end{tabular}

maior que $7 \mathrm{mg} / \mathrm{dl}, 50(48,08 \%)$ apresentaram valores entre 4-7mg/dl, caracterizando sub-deficiência, e 12 (11,54\%) apresentaram valores menores que $4 \mathrm{mg} / \mathrm{dl}$, o que indica deficiência, levando-se em consideração os valores de referência para bovinos estipulados por Riet-Correa \& Timm (2007). Estes valores foram semelhantes aos encontrados por Cardoso et al. (1994) em bubalinos em regime de pasto, no Estado do Pará, com idade de seis e quatorze meses, que verificaram médias de $6,30 \mathrm{mg} / \mathrm{dl} \pm 1,81$ e $5,25 \mathrm{mg} / \mathrm{dl} \pm 1,88$ de fósforo, respectivamente, e por Oliveira et al. (2009), que encontraram média de $5,51 \mathrm{mg} / \mathrm{dl} \pm 1,03$ de fósforo em bubalinos adultos, criados extensivamente sem suplementação, nos municípios de Soure e Chaves na llha de Marajó.

Os níveis que indicaram sub-deficiência e deficiência de fósforo inorgânico equivaleram juntos a $59,62 \%$ dos animais estudados, demonstrando a ocorrência de baixos níveis séricos de fósforo em bubalinos da llha de Marajó. Níveis deficientes e sub-deficientes também foram observados por Lau (1988) estudando búfalos com sinais clínicos de deficiência de fósforo no Estado do Pará, com idade entre quatro e seis anos e por Barbosa et al. (2007) em estudo realizado em 157 amostras de soro sanguíneo de búfalos jovens e adultos, com sinais clínicos severos de deficiência de fósforo, de uma propriedade da llha de Marajó.

O valor médio de fósforo no osso foi de $10,77 \% \pm 2,00$, valor este inferior ao considerado como valor normal para a espécie bovina, que é de 11,5\% (McDowell et al. 1984). Verificou-se que $51(57,30 \%)$ animais apresentaram níveis baixos e $38(42,70 \%)$ animais estavam dentro da normalidade. Níveis semelhantes foram encontrados em um estudo realizado por Cardoso (1997) com búfalos deficientes de fósforo na llha de Marajó, que revelou média de 10,50\%. Valores médios baixos de fósforo no osso também foram observados em bovinos por Sousa et al. 1985, no Mato Grosso do Sul, e por Sousa et al. 1986, em Roraima.

A média da densidade específica e do percentual de cinzas no tecido ósseo foi de $1,59 \mathrm{~g} / \mathrm{ml} \pm 0,18$ e $60,87 \%$ $\pm 2,17$, respectivamente. Estes teores são considerados inferiores aos de referência para bovinos, que é $1,69 \mathrm{~g} / \mathrm{ml}$ para a densidade específica (Valdes et al. 1988) e 66,8\% para o percentual de cinzas (Little 1972). Verificou-se que $63(70,79 \%)$ animais apresentaram baixa densidade específica do osso e $26(29,21 \%)$ animais estavam dentro da normalidade. Verificou-se também que todos os animais apresentaram baixo percentual de cinzas no osso. SemeIhantes resultados, também foram observados por Pereira \& Cardoso (2009), em um estudo com 110 bubalinos deficientes em fósforo criados na llha de Marajó, que verificaram médias de $1,46 \mathrm{~g} / \mathrm{ml}$ para a densidade específica e $60,24 \%$ no percentual de cinzas. Trabalhos realizados por Shupe et al. (1988) e Pereira et al. (2003), ressaltam a ocorrência da diminuição da densidade óssea em bubalinos e bovinos com deficiências de fósforo e cobre. Sousa et al. (1982) e Lisbôa et al. (1996) também relatam baixos índices de cinzas no osso de bovinos.

Considerando que os valores da densidade específica e do percentual de cinzas do osso estão diretamente relacionados ao status de fósforo no organismo animal, e que estes, assim como o nível de fósforo no osso e no soro sanguíneo estavam abaixo dos limites críticos, observase que os bubalinos desse estudo apresentaram baixa reservas de fósforo no organismo, caracterizando deficiência deste mineral.

Das 104 amostras de fígado estudadas, 21 (20,19\%) na detecção do cobalto e $24(23,07 \%)$ na detecção do cobre apresentaram valores abaixo do limite de detecção da metodologia empregada. Considerando que o limite de detecção é de 0,003ppm para o cobalto e 0,002ppm para o cobre e que segundo Underwood (1977), o nível crítico de cobalto é $0,05 \mathrm{ppm}$ e de cobre é $100 \mathrm{ppm}$, certificamos que as amostras que não foram detectadas pela metodologia são deficientes nesses elementos.

O nível médio de cobre nas amostras que foram detectadas pela metodologia foi de $5,57 \mathrm{ppm} \pm 7,60$, sendo que todos os animais (inclusive os que não foram detectados pela metodologia) apresentaram níveis de cobre inferiores a 50ppm, o que segundo Underwood (1977), caracteriza deficiência para este elemento. Estes valores são semeIhantes aos encontrados por Cardoso (1997) e Pereira \& Cardoso (2009) estudando bubalinos na llha de Marajó, que revelaram concentrações deficientes de cobre no fígado, com média de 5,7 e 19,51ppm, respectivamente. Sutmöller et al. (1966) e Tokarnia et al. (1968) estudando amostras de fígado bovino na llha de Marajó, também encontraram níveis deficientes de cobre.

Os níveis de cobalto no fígado detectados pela metodologia apresentaram média de $0,36 \mathrm{ppm} \pm 0,33$, o que segundo Underwood (1977), é considerado dentro da normalidade, quando se compara com valores de referência para bo- 
vinos. No entanto, quando se considera também os níveis que não foram detectados pela metodologia, que sabidamente são inferiores a 0,05ppm, observa-se que, segundo valores de referência estipulados por Underwood (1977), 25 $(24,04 \%)$ animais apresentaram níveis menores que $0,05 p p m$, que indica deficiência, $29(27,88 \%)$ animais apresentaram níveis entre $0,05-0,12 \mathrm{ppm}$, que indica sub-deficiência, e 50 (48,08\%) animais apresentaram níveis adequados de cobalto. Desta forma, quando avaliamos os níveis inferiores a 0,05ppm e o níveis entre 0,05-0,12ppm de cobalto, observamos que juntos, equivaleram a $51,92 \%$ das amostras analisadas, demonstrando que a maioria dos animais estudados apresentam baixas reservas de cobalto no organismo. Valores adequados de cobalto no fígado de bubalinos da llha de Marajó foram observados por Cardoso (1997) que revelou média de 0,98ppm, sendo que todas as amostras apresentavam níveis adequados de cobalto no fígado, diferente do encontrado neste estudo. No entanto, estudos com níveis de cobalto em fígado bovino têm revelado deficiência desse elemento em São Paulo (Correa 1955, 1957, Fernandes et al. 1976), Amapá, Espirito Santo (Tokarnia et al. 1971), Amazonas, Pará (Camargo 1980, Barros et al. 1981); Mato Grosso, Roraima, Amazonas, São Paulo e Rio de Janeiro (Moraes 1999).

O valor médio de zinco foi de 27,05ppm $\pm 13,12$, com valores que variaram de 12,07 a $76,11 \mathrm{ppm}$. Todas as amostras analisadas apresentaram valores menores que 100ppm, sendo considerados deficientes quando comparados com níveis adequados para bovinos (Underwood 1977). Estes valores foram diferentes dos observados por Cardoso (1997) que encontrou níveis adequados de zinco no fígado de bubalinos na Ilha de Marajó, com média de 123,00ppm. Camargo et al. (1985) trabalhando com bovinos no Estado do Pará, verificaram valores hepáticos de Zn dentro da normalidade. No entanto, Sousa \& Darsie (1985) no Estado de Roraima e Moraes (1998) no Estado do Ceará e do Piauí, estudando bovinos, determinaram níveis de zinco no fígado abaixo do normal.

A partir das análises do tecido hepático dos bubalinos, verificou-se a ocorrência de deficiência de cobre, cobalto e zinco, pelos baixos teores destes elementos no fígado. Vale ressaltar, que na determinação de cobre e zinco todos os animais estudados apresentaram concentrações abaixo dos níveis críticos, demonstrando uma maior gravidade nesses elementos.

Levando em consideração que os animais desse estudo foram criados de forma extremamente extensiva, nos campos naturais da llha de Marajó, que sabidamente possuem solos distróficos, pastagens nativas de baixa qualidade nutricional e quase sempre não se realiza suplementação mineral, justifica-se a ocorrência das deficiências de fósforo, cobre, cobalto e zinco nos bubalinos estudados.

Os resultados do presente trabalho demonstraram que a análise dos baixos níveis de fósforo, no soro sanguíneo e no osso, da densidade específica e do percentual de cinzas no osso caracterizou a existência da deficiência de fósforo nos animais da Ilha de Marajó. Na determinação de cobalto, cobre e zinco no fígado, verificou-se que os bubalinos apresentavam deficiência nesses elementos, sendo que as deficiências de cobre e zinco demonstraram maior gravidade, pois todos os animais estudados apresentavam níveis deficientes. As determinações da densidade específica do osso e do percentual de cinzas óssea serviram como um bom indicativo no diagnóstico da deficiência de fósforo. Com isso, verifica-se a necessidade da suplementação mineral com fósforo, cobre, cobalto e zinco aos bubalinos da Ilha de Marajó.

Agradecimentos.- Ao Conselho Nacional de Desenvolvimento Científico e Tecnológico (CNPq), pela concessão da bolsa de mestrado. À Fundação de Amparo à Pesquisa do Estado do Pará (FAPESPA), pelo apoio financeiro para realização deste projeto, e ao Instituto Evandro Chagas, pela realização das determinações dos minerais.

\section{REFERÊNCIAS}

Barbosa J.D., Oliveira C.M.C., Duarte M.D. \& Silveira J.A.S. 2005. Doenças de búfalos na Amazônia. Anais II Simpósio Mineiro de Buiatria, Belo Horizonte, Minas Gerais.

Barbosa J.D., Oliveira C.M.C., Duarte M.D., Albernaz T.T., Oliveira C.A., Riet-Correa G. \& Riet-Correa F. 2007. Phosphorus deficiency in buffaloes in the state of Pará, northern Brazil. Italian J. Anim. Sci. 6(2):971-973.

Barros N.N., Teixeira Brito L., Moraes E., Canto A.C. \& Italiano E.C. 1981. Teores de minerais no complexo solo-planta-animal de áreas de terra firme do Amazonas. Comunicado Técnico 16, EmbrapaUepae, Manaus. 3p.

Boyazoglu P.A., Barrett E.L., Young E. \& Ebedes H. 1972. Liver mineral analysis as indicator of nutritional adequacy. Proc. $2^{\text {nd }}$ World Conference of Animal Nutrition, Madrid, p.995-1008.

Camargo W.V.A., Fernandes N.S. \& Santiago A.M.H. 1980. Estudos de elementos minerais de interesse pecuário em regiões da Amazônia legal. Arqs Inst. Biológico, São Paulo, 47:83-111.

Camargo W.V.A., Santiago A.M.H., Nazário W. \& Chiba S. 1985. Teores de minerais de interesse pecuário em regiões da Polamazônia. Revta Bras. Med. Vet. 7(4):118-124.

Cardoso E.C. 1997. Nutricão mineral em bubalinos e bovinos nos campos do Marajó, Estado do Pará: Cálcio, fósforo, cobre, cobalto, manganês, ferro e zinco. Dissertação de mestrado em Ciências Biológicas, Universidade Federal do Pará, Belém, PA. 75p.

Cardoso E.E., Teixeira Neto J.E., Veiga J.B., Falesi I.C. \& Silva A.V.C. 1994. Contribution of the study of calcium and phosphorus on buffaloes in Marajó island, Brazil. Proc. IV World Buffalo Congress, São Paulo, SP, p.215-217.

Conrad J.H. 1984. Administração racional de suplementos minerais a nível de fazenda. I Simpósio sobre Nutrição Mineral, São Paulo, SP, p.57-67.

Corrêa R. 1955. Carência de cobalto em bovinos no Estado de São Paulo. Revta Bras. Biologia 15:309-313.

Corrêa R. 1957. Carência de cobalto em bovinos. Arqs Inst. Biológico, São Paulo, 24:199-227.

Fernandes N.S., Santiago A.M.H., Camargo W.V.A. \& Vianna S.S.S. 1976. Níveis estacionais de cobre e de cobalto em tecido animal e vegetal. Atualidades Veterinárias, Porto Alegre, 5(28):24-27.

Fick K.R., McDowell L.R., Miles P.H., Wilkinson N.S., Funk J.D., Conrad J.H., Dayrell M.S. \& Rosa I.V. 1980. Métodos de Análises de Minerais em Tecidos de Animais e de Plantas. $2^{\underline{a}}$ ed. University of Florida, Gainesville. 79p.

Hach Company. 2008. Espectrophotometer DR-2800. $2^{\text {nd }}$ ed. Procedures Manual, Germany. 
Lau H.D. 1988. Aspectos sobre desnutrição mineral em búfalos e método de tratamento. Bolm Pesquisa 89, Embrapa-CPATU, Belém. 14p.

Lisbôa J.A.N., Kuchembuck M.R.G., Kohayagawa A., Bomfim S.R.M., Santiago A.M.H. \& Dutra I.S. 1996. Resultados de patologia clínica e dosagens de elementos minerais em bovinos acometidos pelo botulismo epizoótico no Estado de São Paulo. Pesq. Vet. Bras. 16(4): 91-97.

Little D.A. 1972. Bone biopsy in cattle and sheep for studies of phosphorus status. Aust. Vet. J. 48(12):668-670.

McDowell L.R., Conrad J.H. \& Ellis G.L. 1984. Mineral deficiencies and imbalances and their diagnosis. Proc. Symposium on Herbivore Nutrition in Sub-Tropics and Tropics, Problems and Prospects, Pretoria, South Africa, p.67-88.

Mendes M.O. 1977. Mineral status of beef cattle in the northern part of Mato Grosso, Brazil, as indicated by age, season, and sampling technique. Dissertation, University of Florida, Gainesville. 236p.

Miller W.J. \& Stake P.E. 1974. Uses and limitations on biochemical measurements in diagnosing mineral deficiencies. Proc. Nutrition Conference for the Feed Industry. Atlanta, Georgia, p.25-43.

Moraes S.S. 1998. Untersuchungen zu Abhängigkeiten der Zink, Mangan und Selengehalte in Lebern von Rindern aus ausgewählten Regionen Brasiliens. Dissertation, Tierärztliche Hochschule Hannover, Alemanha. $146 p$.

Moraes S.S., Tokarnia C.H. \& Döbereiner J. 1999. Deficiências de microelementos em bovinos e ovinos em algumas regiões do Brasil. Pesq. Vet. Bras. 19(1):19-33.

Nomura C.S., Silva C.S., Nogueira A.R.A. \& Oliveira P.V. 2005. Bovine liver sample preparation and micro-homogeneity study for $\mathrm{Cu}$ and $\mathrm{Zn}$ determination by solid sampling electrothermal atomic absorption spectrometry. Spectrochimica Acta. B 60:673-680.

Oliveira C.H.S., Pinheiro C.P., Campos K.F., Reis A.S.B., Oliveira C.M.C., Duarte M.D. \& Barbosa J.D. 2009. Serum levels of phosphorus in buffalos (Bubalus bubalis) from Marajó Island, Pará, Brazil. Proc. V America's Buffalo Symposium and IV Europe and America's Buffalo Symposium, Pedro Leopoldo, MG, p.114.

Pereira W.L.A. \& Cardoso E.C. 2009. Aspectos histológicos da osteoporose em bubalinos e a condição físico-química óssea e do cobre hepático. Revta Ciênc. Agr. 51:25-36.

Pereira W.L.A., Túry E., Vale W.G. \& Cardoso E.C. 2003. Anatomicalpathological analysis of the bone quality in the diagnosis of osteodystrophy in buffaloes. Bubalus Bubalis 9(2):71-82.

Riet-Correa F. \& Timm C.D. 2007. Deficiência de fósforo, p.248-257.
In: Riet-Correa F., Shild A.L., Lemos R.A.A. \& Borges J.R.J. (Eds), Doenças de Ruminantes e Eqüídeos. Vol.2. Palloti, Santa Maria. $694 p$.

Shupe J.L., Butcher J.E., Call J.W., Olson A.E. \& Blake J.T. 1988. Clinical signs and bone changes associated with phosphorus deficiency in beef cattle. Am. J. Vet. Res. 49(9):1629-1636.

Sousa J.C. \& Darsie G. 1985. Deficiências minerais em bovinos de Roraima, Brasil. I. Zinco e cobalto. Pesq. Agropec. Bras. 20(11):13091316.

Sousa J.C., Conrad J.H., Mott G.O., McDowell L.R. \& Ammerman C.B. 1982. Inter-relações entre minerais no solo, plantas forrageiras e tecido animal no norte do Mato Grosso. 4. Zinco, magnésio, sódio e potássio. Pesq. Agropec. Bras. 17(1):11-20.

Sousa J.C., Gomes R.F.C., Silva J.M.S. \& Euclides V.P.B. 1985. Suplementação mineral de novilhos de corte em pastagens adubadas de capim-colonião. Pesq. Agropec. Bras. 20(2):259-269.

Sousa J.C., Gonçalves E.M., Viana J.A.C. \& Darsie G. 1986. Deficiências minerais em bovinos de Roraima, Brasil. III. Cálcio e fósforo. Pesq. Agropec. Bras. 21(12):1327-1336.

Sutmöller P., Abreu A.V., Grift J. van der \& Sombroek W.G. 1966. Mineral imbalances in cattle in the Amazon valley. Commun. 53, Dept Agric. Research, Amsterdam. 135p + tables.

Tokarnia C.H., Canella C.F.C., Guimarães J.A. \& Döbereiner J. 1968. Deficiências de cobre e cobalto em bovinos e ovinos no Nordeste e Norte do Brasil. Pesq. Agropec. Bras. 3:35I-360.

Tokarnia C.H., Guimarães J.A., Canella C.F.C. \& Döbereiner J. 1971. Deficiências de cobre e cobalto em bovinos e ovinos em algumas regiões do Brasil. Pesq. Agropec. Bras. 6:61-77.

Tokarnia C.H., Döbereiner J., Moraes S.S. \& Peixoto P. 1999. Deficiências e desequilíbrios minerais em bovinos e ovinos: revisão de estudos realizados no Brasil de 1987 a 1998. Pesq. Vet. Bras. 19:47-62.

Tokarnia C.H., Döbereiner J., Peixoto P.V. \& Canella C.F.C. 2000. Deficiências minerais em animais de fazenda, principalmente bovinos. Pesq. Vet. Bras. 20(3):127-138.

Underwood E.J. 1977. Trace Elements in Human and Animals Nutrition. $4^{\text {th }}$ ed. Academic Press, New York. 545p.

Underwood E.J. 1981. The Mineral Nutrition of Livestock. $2^{\text {nd }}$ ed. Commonwealth Agricultural Bureaux, Farnham Royal, England. $180 \mathrm{p}$.

Valdes J.L., McDowell L.R. \& Koger M. 1988. Mineral status and suplementation of grazing beef cattle under tropical conditions in Guatemala. I. Macroelements. J. Prod. Agric. 1(4):347-350. 